\title{
Uma Visão Sobre como se Organiza o Ensino Médio em Classes Multisseriadas em uma Escola Guarani
}

\author{
Adriana Olmos da Rocha ${ }^{1}$ \\ Tania Denise Miskinis Salgado ${ }^{2}$
}

\begin{abstract}
$\underline{\text { Resumo }}$
0 presente estudo analisa de que forma as orientações dos documentos oficiais sobre educação indígena vêm sendo postas em prática na realidade de uma escola situada dentro de uma aldeia Guarani, na Região Metropolitana de Porto Alegre. Utilizou-se uma metodologia de pesquisa qualitativa, numa perspectiva etnográfica. Os dados dos alunos foram colhidos por meio de questionário e os dos professores, indígenas e não indígenas, por entrevistas. Analisou-se a legislação referente à educação indígena no Brasil e buscou-se identificar, nas respostas, como estão sendo desenvolvidos seus pressupostos na realidade desta escola. Os resultados mostram que não há diretrizes curriculares específicas para a educação indígena no Ensino Médio. Foram encontradas diretrizes para o Ensino Fundamental, que valorizam os saberes tradicionais da cultura indígena. Observou-se que nem sempre os pressupostos da legislação para a educação indígena conseguem ser adequadamente aplicados na realidade desta escola, devido à inexistência de material didático específico e de cursos de formação continuada para professores de origem não indígena que atuam nesta modalidade educacional. Quanto às classes multisseriadas, os professores as entendem como uma dificuldade, enquanto os estudantes indígenas apontam a troca de ideias e a ajuda para esclarecer dúvidas dos colegas, em Guarani, como aspectos positivos para a aprendizagem.
\end{abstract}

Palavras-chave: Educação indígena. Ensino Médio. Classes multisseriadas.

${ }^{1}$ Licenciada em Química pela Universidade Federal do Rio Grande do Sul (UFRGS), Porto Alegre-RS. Professora de Química da rede pública estadual do Estado do Rio Grande do Sul. adrolmos@hotmail.com

2 Doutora em Ciências pela Universidade Federal do Rio Grande do Sul (UFRGS). Professora do Departamento de Físico-Química e do Programa de Pós-Graduação em Educação em Ciências: Química da Vida e Saúde da UFRGS, Porto Alegre-RS. tania.salgado@ufrgs.br 


\title{
A LOOK AT HOW HIGH SCHOOL IS ORGANIZED IN THE MULTI-AGED CLASSES OF A GUARANI SCHOOL
}

\begin{abstract}
This work analyzes the ways in which the official orientation documents about indigenous education are being implemented in a school inside a Guarani village, in the Porto Alegre metropolitan area. A qualitative research methodology was used, with an ethnographic perspective. The students' data were collected through a questionnaire, and the indigenous and non-indigenous teachers', through interviews. The Brazilian indigenous education laws and its development in this school's reality were analyzed. The results show that there is no specific curriculum directive for high school indigenous education. Directives for the basic education were found, which value the traditional knowledges of the indigenous culture. It was observed that the laws about indigenous education cannot always be applied in this school's reality because of the lack of specific didactic materials and specific courses for non-indigenous teachers that teach in this type of school. Regarding the multi-aged classes, the teachers see it as a problem, while the students see the idea exchange and classmates' help in the Guarani language with misunderstandings as positive aspects.
\end{abstract}

Keywords: Indigenous education. High School. Multi-aged classes.

Recebido em: 12/2/2017

Aceito em: 2/10/2017 
A legislação que regula a educação indígena no Brasil objetiva garantir educação diferenciada e de qualidade para essa parcela da população brasileira. Vem apresentando avanços desde a década de 70 do século 20, porém ainda com grandes obstáculos a serem superados. As escolas indígenas têm procurado adaptar os seus currículos de modo a torná-los mais próximos de sua realidade e mais condizentes com as demandas de seus povos, uma vez que a proposta pedagógica que lhes foi imposta ao longo da História não corresponde aos seus interesses políticos e nem está de acordo com as tradições de sua cultura.

A Constituição de 1988 e a Lei de Diretrizes e Bases da Educação Nacional (LDB) garantem aos povos indígenas o direito de estabelecerem formas particulares de organização escolar, como um calendário próprio e lhes asseguram, também, grande autonomia no que se refere à criação, ao desenvolvimento e à avaliação dos conteúdos a serem incorporados em suas escolas (RIO GRANDE DO SUL, 2002).

De modo geral, a educação é concebida para uma sociedade tida como homogênea, embora sabidamente não o seja. No caso da educação indígena, deve-se considerar ainda a grande diversidade étnica e cultural e as especificidades dos povos indígenas. É necessário que os professores dessas escolas sejam capazes de fazer uma análise crítica das práticas curriculares a fim de garantir o exercício pleno da cidadania, da interculturalidade e do respeito as suas particularidades linguísticas e culturais, de modo que se possa falar em uma escola indígena diferenciada e de qualidade.

A educação e o conhecimento dos povos indígenas vêm sendo produzidos, armazenados, transmitidos e reelaborados historicamente, desde antes da institucionalização da escola. Os seus conhecimentos científicos e filosóficos são fruto de muita observação, experimentação, estabelecimento de relações e formulações de princípios capazes de explicar os fenômenos observados. Esses povos produziram um rico acervo de informações e reflexões sobre a natureza e sobre os mistérios da existência humana. Assim, um aspecto que deve ser considerado no trabalho da escola indígena é a valorização da oralidade. As habilidades de ouvir em silêncio, armazenar as informações e retransmitir os conhecimentos por essa mesma via são aspectos fundamentais de transmissão de conhecimento e cultura no meio indígena. 
Diante disso, quando se pensa em educação indígena, deve-se ter claro que a escola não é o único lugar de aprendizado, pelo contrário, a comunidade e seus membros, professores indígenas, conselhos de pais e anciãos têm uma sabedoria para ser transmitida, que é o conjunto de valores próprios e tradicionais da cultura indígena. Esses conhecimentos não são incompatíveis com os conhecimentos da escola contemporânea, na verdade eles fazem parte de um conjunto de saberes capazes de contribuir com a formação escolar (BRASIL, 1998a).

O objetivo geral do presente estudo é analisar de que forma as orientações que constam nos documentos oficiais a respeito de educação indígena vêm sendo postas em prática na realidade de uma escola indígena situada dentro de uma aldeia Guarani, na Região Metropolitana de Porto Alegre.

Como objetivos específicos, pretende-se:

- Fazer um levantamento, na legislação vigente, das orientações para a educação indígena, enfocando principalmente os aspectos relativos ao Ensino Médio e às Ciências da Natureza.

- Analisar como os professores e a direção dessa escola indígena percebem essa legislação, como fazem para instituir seus pressupostos, quais os aspectos que consideram bem atendidos e quais as dificuldades.

- Analisar como os próprios alunos indígenas percebem o ensino que recebem, se consideram que os temas abordados são relevantes, se a metodologia está adequada ou não à oralidade da sua cultura e como se sentem nas classes multisseriadas.

\section{Pressupostos Teóricos da Educação Indígena}

A educação indígena vem conquistando reconhecimento nas últimas décadas, buscando preservar a sua cultura e, ao mesmo tempo, possibilitar sua integração na sociedade moderna. A educação escolar Indígena nasce da diversidade, autonomia e liberdade de pensar o mundo, valores e significados de cada um dos povos indígenas. 
Uma peculiaridade dos povos indígenas é que os seus territórios não coincidem com as divisões político-administrativas em Estados e municípios. Assim, por exemplo, os territórios do povo Guarani Mbyá distribuem-se ao longo da costa brasileira em seis Estados: Espírito Santo, Rio de Janeiro, São Paulo, Paraná, Santa Catarina e Rio Grande do Sul (BRASIL, 2007). Para Martins (2013, p. 283), “os Guaranis são um povo caminhante e a língua é um importante traço de identidade, pois permite que permaneçam vivas as suas raízes". Assim sendo, a língua garante a unidade desse povo por tão vasto território. Neste contexto, ações educacionais voltadas à afirmação das identidades étnicas, à recuperação das memórias históricas, à valorização das línguas e conhecimentos dos povos indígenas fundamentam a ampliação da oferta de educação básica intercultural de qualidade. Segundo Martins (2013, p. 278), "somente o diálogo com os indígenas e entre os indígenas pode apontar o caminho para uma escola diferenciada e de qualidade".

Estas escolas, construídas dentro de terras indígenas e com o objetivo de atender a essa população, nem sempre são assim entendidas. "Os Guaranis afirmam que mesmo funcionando em suas aldeias, [a escola] é de 'branco', deixam subentendido que a compreendem como constituída e constituidora de uma outra concepção de mundo, de uma outra ordem, a ordem ocidental" (BERGAMASCHI, 2007a, p. 122).

A mesma autora, no entanto, afirma que

[...] é nos pequenos gestos cotidianos, sustentados pelas características de sua educação tradicional - a curiosidade, a observação, a imitação e o respeito, entre outros atributos responsáveis pela confecção da pessoa Guarani - que se apropriam da escola, tornando-a sua (B2007a, p. 130).

Sob esse ponto de vista, mesmo a escola não sendo do seu mundo, está bem inserida nele.

Segundo o Censo realizado em 2010 pelo Instituto Brasileiro de Geografia e Estatística (Instituto..., 2011), a população indígena brasileira soma 817.963 indivíduos, com 305 diferentes etnias distribuídas nas cinco regiões do Brasil, 
falando 274 diferentes línguas. Desse modo, existe uma diversidade cultural e linguística a ser preservada e, segundo o Referencial Curricular Nacional para as Escolas Indígenas (RCNEI),

[...] soma de experiências históricas e sociais diversificadas, de elaborados saberes e criações, de arte, de música, de conhecimentos, de filosofias originais, construídos ao longo de milênios pela pesquisa, reflexão, criatividade, inteligência e sensibilidade de seus membros. (...) Sua variedade e sua originalidade são um patrimônio importante não apenas para eles próprios e para o Brasil, mas, de fato, para toda a humanidade (BRASIL, 1998a, p. 22).

É relevante compreender a diversidade implícita na pluralidade étnica para a formulação de políticas e ações adequadas às realidades de cada povo indígena. Por isso, não são condizentes com essa realidade propostas que tomem os povos indistintamente, sem contemplar suas especificidades em termos culturais e linguísticos.

Pensar em Escola Indígena específica é pensar no respeito, no incentivo à língua materna e no seu uso e o professor é o interlocutor capaz de manter o diálogo. É pensar também no diálogo com os mais velhos, buscando um aporte de conhecimentos que permitam a educação diferenciada (MARTINS, 2013, p. 288).

Também é importante a distinção entre educação indígena e educação escolar indígena. Deve-se ter claro que para o indígena a educação não se dá exclusivamente no ambiente escolar, pelo contrário. Para os Guaranis, os conhecimentos não necessitam da escola para se sustentarem. A vida em comunidade, dentro de um conjunto de valores, de uma cosmologia que identifica, unifica e constrói o "Nhande Reko, ${ }^{3}$ prescindem da escola, que é o espaço destinado à aprendizagem da escrita e tecnologias necessárias para a inter-relação com o universo não indígena. É preciso, portanto, reconhecer os diversos espaços educativos em que o aluno indígena transita (MARTINS, 2013). A prática pedagógica

3 Nhande Reko: "Nosso modo de ser". O modo de ser Guarani, sua cultura, também denominada Guarani. 
deve ser pensada em um contexto de diversidade, de acordo com características que se tornaram definidoras da escola indígena como uma categoria específica da Educação Básica: a interculturalidade, o bilinguismo ou multilinguismo, a especificidade, a diferenciação e a participação comunitária (BRASIL, 2007).

A interculturalidade considera a diversidade cultural no processo de ensino e de aprendizagem. A escola deve trabalhar com os valores, saberes tradicionais e práticas de cada comunidade e garantir o acesso a conhecimentos e tecnologias relevantes para o processo de interação e participação cidadã na sociedade não indígena. "A escola é uma necessidade para conviver com os não indígenas, compreender a sociedade e poder lutar pelos seus direitos" (MARTINS, 2013, p. 279).

De acordo com Lopes (2015, p. 249), "há uma forma específica de apropriação da educação escolar pelo povo indígena (ou cada comunidade) que orienta a relação que cada comunidade mantém com a escola e com os conhecimentos veiculados por ela." Com isso, as atividades curriculares devem ser significativas e contextualizadas às experiências dos educandos e de suas comunidades. As escolas indígenas propõem-se a ser espaços interculturais, nos quais se debatem e se constroem conhecimentos e estratégias sociais sobre a situação de contato entre diferentes etnias. Assim, a escola indígena será específica a cada projeto societário e diferenciada em relação a outras escolas, sejam de outras comunidades indígenas, sejam das escolas não indígenas:

Pensar em Escola Indígena específica é pensar no respeito, no incentivo à língua materna e no seu uso e o professor é o interlocutor capaz de manter o diálogo. É pensar também no diálogo com os mais velhos buscando um aporte de conhecimentos que permitam a educação diferenciada (MARTINS, 2013, p. 288).

A escola indígena se caracteriza por ser comunitária, ou seja, espera-se que esteja articulada com os anseios da comunidade e a seus projetos de sustentabilidade territorial e cultural. Dessa forma, a escola e seus profissionais devem ser aliados da comunidade e trabalhar a partir do diálogo e participação 
comunitária, definindo desde o modelo de gestão e calendário escolar - o qual deve estar em conformidade com as atividades rituais e produtivas do grupo até os temas e conteúdos a serem trabalhados.

As escolas precisam estar integradas às demais atividades que permeiam a aldeia, sem contrapor valores ou sobrepor conhecimentos. Essa integração vem da necessidade de compreender o aluno indígena, observar o seu desenvolvimento acima de tudo, reconhecer que existem outros espaços de aprendizagem formadores do indivíduo e que precisam ser considerados (MARTINS, 2013, p. 280).

Os povos indígenas têm garantido o direito a que os processos de aprendizagem escolares sejam feitos na língua materna dos educandos, trazendo a realidade sociolinguística da comunidade onde está inserida a escola para o uso das línguas tanto no espaço comunitário quanto no escolar. Esta característica da escola indígena passa hoje por uma reflexão entre professores indígenas e comunidade escolar, tendo em vista a manutenção e a revitalização das línguas maternas e aprendizagem da língua portuguesa com metodologias de aquisição de segunda língua. Considerar os direitos linguísticos das crianças nas escolas indígenas significa, então, conhecer a realidade sociolinguística da comunidade, fortalecer e valorizar a língua indígena em seu uso como língua de instrução, de comunicação e também dos materiais didáticos.

Os Guaranis fortalecem sua língua na oralidade, sua visão de mundo é passada de geração a geração. Assim mantêm sua comunicação entre os povos, pela sua característica de migração. A palavra para eles tem um significado muito forte. Preocupam-se ao pronunciá-la, utilizam entonações para dar ênfase e o devido valor ao que estão pronunciando, cultuam o falar e escutar conscientes. "A oralidade, traço forte da cultura indígena, está presente não apenas na fala, mas na escuta respeitosa e atenta à palavra" (BERGAMASCHI; SILVA, 2008, p. 136).

Os anciãos têm um papel importante para o povo Guarani, é por eles que a educação tradicional é socializada. O conhecimento popular é assimilado pelas crianças no seu meio social, sendo a escola admitida pela necessidade da convivência com a cultura envolvente dos não índios (BERGAMASCHI; SILVA, 
2008). Para os Guaranis a educação e a religião estão intimamente ligadas. É na "Opy" que acontece a mais importante socialização dos conhecimentos. É por meio dos cantos, danças, orações e rituais que envolvem o coletivo da aldeia que eles mantêm viva a cultura e buscam reforçar a própria identidade. Para Martins (2013, p. 279),

a educação Guarani tem na "Opy" a sua referência maior. Os conhecimentos transmitidos pelos "Karaî" [...] Os conhecimentos tradicionais da "Opy" dizem respeito apenas aos Guaranis, por isso não gostam que sejam divulgados, pois o "juruá" "não tem a mesma formação espiritual e os mesmos valores. A educação tradicional sai de dentro de casa ("Opy”), por isso tem que preservar, não ficar mostrando.

Por essa razão os Guaranis não gostam que os não indígenas frequentem a casa de rezas, salvo em ocasiões muito especiais. É nos rituais de nominação das crianças, no respeito aos ensinamentos do "Karâ̂" e principalmente a fé em "Nhanderu" que mantêm a sua tradição. A "Opy" já foi denominada pelos professores Guarani como "a nossa universidade" (BERGAMASCHI; SILVA, 2008, p. 135). E é na “Opy" que os ensinamentos são passados de forma oral e respeitando as idades.

\section{A Legislação Brasileira Relativa à Educação Indígena}

A escola para índios no Brasil começou a se estruturar a partir de 1549, quando chegou ao território nacional a primeira missão jesuítica enviada de Portugal por D. João III, porém era imposta com o intuito colonizador, integralista e “civilizador”, sem respeitar a sua cosmologia, e assim foi por um longo período.

${ }^{4}$ Opy: casa tradicional de reza. Lugar sagrado do "estar junto" espacial e temporal do povo Guarani

5 Karaí: chefe espiritual responsável pelo cuidado na aldeia Guarani.

6 Juruá: boca cabeluda, homem de bigode, homem não indígena. É a forma como os índios Guaranis chamam as pessoas não indígenas, independentemente de sua origem étnica.

7 Nhanderu: nosso pai, Deus, sagrado, criador das belas palavras. 
Com a aprovação da Constituição Federal de 1988, as leis referentes aos povos indígenas reconheceram a cidadania e os seus direitos e deveres, bem como o direito a um ensino diferenciado, voltado para o desenvolvimento das práticas culturais destes povos. No artigo 210 , parágrafo $2 .^{\circ}$, a Constituição reconhece às comunidades indígenas a utilização de suas línguas maternas e processos próprios de aprendizagem.

Em 1996, a Lei de Diretrizes e Bases da Educação Nacional - LDB (BRASIL, 1996) detalhou os princípios estabelecidos na Constituição Federal. No artigo 32 da LDB, o parágrafo $3^{\circ}$ assegura às comunidades indígenas "a utilização de suas línguas maternas e processos próprios de aprendizagem”. O artigo 78 da LDB estabelece que a educação escolar indígena deve ser bilíngue e intercultural, com os seguintes objetivos:

I - Proporcionar aos índios, suas comunidades e povos, a recuperação de suas memórias históricas; a reafirmação de suas identidades étnicas; a valorização de suas línguas e ciências.

II - Garantir aos índios, suas comunidades e povos, o acesso às informações, conhecimentos técnicos e científicos da sociedade nacional e demais sociedades indígenas e não índias (BRASIL, 1996).

O artigo 79 da LDB incumbe a União de apoiar técnica e financeiramente programas integrados de ensino e pesquisa, planejados com anuência das comunidades indígenas, tendo por objetivos:

I) fortalecer as práticas socioculturais e a língua materna de cada comunidade indígena; II) manter programas de formação de pessoal especializado, destinado à educação escolar nas comunidades indígenas; III) desenvolver currículos e programas específicos, neles incluindo os conteúdos culturais correspondentes às respectivas comunidades; IV) elaborar e publicar sistematicamente material didático específico e diferenciado (BRASIL, 1996).

Esses dispositivos da LDB foram regulamentados pelo Conselho Nacional de Educação por meio da Resolução CNE/CEB n. ${ }^{\circ}$ 3, de 10 de novembro de 1999 (BRASIL, 1999), que fixa as Diretrizes Nacionais para o Funcionamento das Escolas Indígenas. Para uma escola ser considerada indígena, deve estar em 
terras habitadas por comunidades indígenas e atender exclusivamente a essas comunidades; o ensino deve ser ministrado na língua materna das comunidades atendidas, como uma das formas de preservação da realidade sociolinguística de cada povo e deve ter organização escolar própria. As mesmas diretrizes garantem ainda o direito das populações indígenas a um calendário escolar diferenciado, de acordo com sua cultura e suas necessidades.

A formação de professores para atuação nas escolas indígenas também é normatizada pela Resolução CNE/CEB n. ${ }^{\circ}$ 3/1999. Em seu artigo $8^{\circ}$, estabelece que a atividade docente na escola indígena "será exercida prioritariamente por professores indígenas oriundos da respectiva etnia". Para isso, em seu artigo $6^{\circ}$, parágrafo único, garante "aos professores indígenas a sua formação em serviço e, quando for o caso, concomitantemente com a sua própria escolarização”.

No Rio Grande do Sul, o Parecer n. ${ }^{\circ} 383$ do Conselho Estadual de Educação, de 28 de março de 2002, estabelece normas para o funcionamento das escolas indígenas no sistema estadual de ensino. Entre suas determinações, assegura que a escola indígena deve ser específica e diferenciada, bilíngue ou multilíngue, intercultural e comunitária (RIO GRANDE DO SUL, 2002). E retoma, em âmbito estadual, a importância da oralidade na cultura indígena, reafirmando que é necessário

pensar a escola a partir das concepções indígenas do mundo e do homem e das formas de organização social, política, cultural, econômica e religiosa desses povos. Da reflexão sobre suas trajetórias (memórias, experiências, histórias,..), de suas teorias sobre o cosmos e sobre os seres, dos significados que construíram para as coisas e os acontecimentos, nascem visões diferentes de mundo, expressas na música, nos mitos, nos rituais, nos discursos, entre outros (RIO GRANDE DO SUL, 2002).

Esse é um aspecto importante para se ter em conta quando se pensa em trabalhar, por exemplo, conceitos da área das Ciências da Natureza com alunos indígenas, pois é necessário negociar significados dos fenômenos estudados, respeitando a cultura indígena, mas também buscando nela elementos que possam aproximar as duas visões a respeito da natureza. O Parecer 383/2002 salienta, ainda, a importância da utilização da língua materna da comunidade na escola, 
ao lado da "língua de instrução", para introduzir conceitos, dar esclarecimentos e explicações. É por meio dela que professores e alunos devem discutir conceitos de Matemática, Geografia, História, etc., e assim oportunizar a aprendizagem de novos conhecimentos aos alunos que não dominam a língua portuguesa, fortalecer a língua indígena e qualificar a competência dos alunos, que poderão utilizá-la para falar sobre novos assuntos, ampliando seu vocabulário.

Em âmbito nacional, o Referencial Curricular Nacional para a Educação Escolar Indígena - RCNEI (BRASIL, 1998b) apresenta uma proposta formativa que pretende garantir os pontos comuns, encontrados em meio à desejada diversidade e multiplicidade das culturas indígenas, tal como estão garantidos nos princípios legais anteriormente apresentados. Seu objetivo é oferecer subsídios para a elaboração de programas de educação escolar que atendam aos anseios e interesses das comunidades indígenas.

No Rio Grande do Sul, as culturas indígenas Kaingang e Guarani constituem a base dos currículos escolares para a educação diferenciada que contemple a cultura de cada povo. No cotidiano escolar, entretanto, segundo vários autores, estas leis não chegam a se concretizar de forma plena, o que leva a situações como esta, relatada pelo líder indígena Eloir no texto de Hofmann (2004):

Na realidade, lá no papel está escrito: escola diferenciada, educação diferenciada para os Guaranis, para todo índio, diferenciada. Mas só que vem na escola... a escola é criada na aldeia, e a realidade não é essa, a prática não está sendo isto.

Tassinari (2001) identifica estas "dificuldades de operacionalizar, em termos governamentais e administrativos, os direitos indígenas garantidos legalmente, como saúde e educação diferenciada" (p. 61) e situa a escola indígena num espaço intersticial, que deve ser pensado como "fronteira":

[...] Considero adequado definir as escolas indígenas como espaços de fronteiras, entendidos como espaços de trânsito, articulação e troca de conhecimentos, assim como espaços de incompreensões e redefinições identitárias dos grupos envolvidos nesse processo, índios e não índios (2001, p. 50). 
Assim sendo, espera-se que a educação escolar indígena venha a colaborar com estas comunidades para a sua inserção na sociedade dita por eles "branca", mas com a preservação da sua língua e costumes, possibilitando que escutem outros saberes para interpretá-los e utilizá-los de formas variadas.

\section{O Ensino de Ciências e a Educação Indígena}

Nesta seção serão analisadas algumas das recomendações do RCNEI para o ensino de conceitos da área de Ciências, entretanto é preciso observar que esse Referencial dirige-se ao Ensino Fundamental. A pesquisa da legislação mostrou que não há referenciais oficiais para o ensino de Ciências da Natureza no Ensino Médio indígena.

De acordo com o Referencial Curricular Nacional para a Educação Indígena,

[...] no ensino das Ciências Naturais, procura-se levar os índios a compreender a lógica, os conceitos e princípios da Ciência ocidental, para que possam dialogar em condições de igualdade com a sociedade e, além disso, usufruir dos recursos tecnológicos ocidentais importantes para a garantia da sua sobrevivência física e cultural. O ensino de Ciências também pode contribuir para que os povos indígenas compreendam melhor as transformações do mundo pelo ser humano, pelo efeito dos avanços tecnológicos e científicos e as suas aplicações (BRASIL, 1998a, p. 254).

Percebe-se o incentivo a estudos direcionados para a busca de respostas sobre fenômenos observados no meio em que os alunos estão inseridos, a fim de dar significado a esse estudo para, a partir dele, incluir novos conhecimentos. As sociedades indígenas vêm produzindo conhecimentos sobre o ser humano e a natureza. Esse poder de observação e a capacidade de passar oralmente esses conhecimentos através das gerações têm sido utilizados na pesquisa científica, contribuindo inclusive para o melhor conhecimento dos ambientes brasileiros.

De acordo com o RCNEI, “aprender ciências é sempre um desafio, pois muitas vezes é necessário superar ideias que parecem óbvias a partir das observações cotidianas. $\mathrm{O}$ estudo de ciências pode ajudar a resolver problemas que 
afetam diretamente as sociedades indígenas" (BRASIL 1998a, p. 241). Física, Química e Biologia podem ser trabalhadas em diferentes graus de profundidade, no Ensino Fundamental - e essas temáticas podem ser estendidas ao Ensino Médio - por meio de temas como saúde, conservação da biodiversidade, gestão territorial, ciência e tecnologia, lixo, água, clima, temperatura, ar, minerais, solos e energia, entre outros.

A área das Ciências da Natureza pode então contribuir para a reflexão e o registro escrito de conhecimentos tradicionais, buscando preservar a cultura desse povo. De acordo com o RCNEI, "para isso é preciso perguntar para as pessoas certas" (BRASIL 1998a, p. 243), ou seja, trazer a comunidade para dialogar com a escola a fim de que esta de fato seja comunitária e atenda às demandas locais.

Nesse sentido, Mortimer (2000) afirma que os alunos das escolas indígenas passam por um processo de entrada numa nova dimensão da cultura, a ciência. E essa nova dimensão "está mais relacionada a entrar num mundo que é ontologicamente e epistemologicamente diferente do mundo cotidiano" (p. 65) das populações indígenas.

\section{Metodologia}

Esta pesquisa foi realizada, no segundo semestre de 2015, com a turma de Ensino Médio indígena multisseriada de uma escola situada dentro de uma aldeia Guarani, na Região Metropolitana de Porto Alegre, RS. Esta Escola Estadual Indígena oferece apenas o Ensino Fundamental. Próximo a ela existe uma Escola Estadual do Campo, de Ensinos Fundamental e Médio. No ano de 2006, por uma demanda desta comunidade indígena Guarani, foi feito um acordo com o Ministério Público Estadual, garantindo aos alunos indígenas o direito de estudar também no Ensino Médio em turmas separadas dos alunos não indígenas. Para isso, a escola indígena de Ensino Fundamental "empresta" uma sala para o Ensino Médio e, portanto, as turmas de Ensino Médio pertencem a uma escola (a Escola do Campo), mas funcionam em outra (a Escola Indígena). 
Atualmente a Escola Indígena conta com um total de 68 alunos, dos quais 10 estão matriculados no Ensino Médio. São sete professores, todos não indígenas e vinculados à Escola do Campo, atendendo a esta única turma de Ensino Médio, sendo que seis deles ministram mais de uma disciplina. A turma é multisseriada, pois a Coordenadoria Regional de Educação não autoriza turmas separadas, devido ao reduzido número de estudantes.

Com o objetivo de levantar a situação destas turmas de Ensino Médio no que diz respeito à aplicação da legislação e às expectativas desta comunidade, é que o presente estudo se estrutura. Para tanto foi realizada uma análise da legislação vigente, que originou as perguntas feitas aos sujeitos da pesquisa.

Antes de iniciar a coleta de dados foi realizada uma reunião com o cacique da aldeia, que também é professor na escola, para explicar a pesquisa e o seu propósito. Isso é muito importante para se respeitar a cultura dos indígenas e para que eles aceitem o trabalho e a pesquisadora (a primeira autora do presente trabalho), mesmo sendo esta uma das professoras da escola e desta turma de Ensino Médio, com interação contínua, há dez anos, com esta Escola Indígena. Após a autorização, todos os participantes foram esclarecidos sobre a pesquisa e assinaram termo de consentimento.

Esta pesquisa constitui-se, portanto, como uma pesquisa de cunho qualitativo, de acordo com Lüdke e André (2005), pois tem o ambiente natural da pesquisadora como fonte direta dos dados e ela própria como instrumento fundamental da pesquisa. Além disso, o caráter da pesquisa é descritivo, com foco no significado que os sujeitos dão aos fatos, não havendo preocupação com dados quantitativos. Por ter contato estreito, direto e prolongado com a comunidade estudada, muitas das análises foram feitas considerando a perspectiva dos participantes, captada pela pesquisadora ao longo de todo o seu período de interação com a comunidade indígena Guarani estudada. Nesse sentido, pode-se afirmar que a pesquisa tem também uma perspectiva etnográfica, de acordo com Angrosino (2009), pois se baseia em pesquisa de campo de longo prazo e personalizada, uma vez que a pesquisadora está, no dia a dia, face a face com 
as pessoas estudadas, sendo tanto participante quanto observadora das vidas em estudo. É multifatorial, pois usa questionários e entrevistas como técnicas de coleta de dados, sendo conduzida de modo indutivo, dialógico e holístico.

Os alunos responderam a um questionário por escrito. Inicialmente pensou-se em fazer entrevistas orais e individuais, porém quando essa proposta foi feita, os alunos preferiram escrever as suas respostas individualmente. Então cada um dos dez alunos pegou um questionário impresso e foi procurar um lugar ao sol ou debaixo de uma árvore, em que pudesse responder tranquilamente. Como os indígenas se expressam, em português, de uma maneira bastante singular, suas respostas foram transcritas fielmente.

Entrevistas semiestruturadas foram realizadas individualmente com os professores indígenas da escola, que atendem apenas às turmas de séries iniciais do Ensino Fundamental, com os professores não indígenas que atendem ao Ensino Médio e com a diretora da escola. As entrevistas foram gravadas e transcritas. Apenas dois professores não indígenas preferiram responder por escrito. Todas as respostas foram depois analisadas em conjunto, procurando-se criar categorias que permitissem concluir a respeito dos aspectos apontados nos objetivos do trabalho.

\section{Resultados e Discussão}

\section{As impressões dos alunos do Ensino Médio}

A primeira pergunta do questionário pretendia investigar se os alunos já haviam estudado em outra escola que não fosse indígena. Apenas dois deles responderam que sim, ambos oriundos de localidades onde não existia escola indígena e, por isso, seus primeiros anos de escolarização ocorreram em escolas não indígenas.

Esta escolarização em escolas não indígenas é difícil e por vezes traumatizante, uma vez que para o indígena o rito de sentar à beira do fogo ao fim das tardes é um momento muito importante para a construção e afirmação da identidade. É nesse lugar que os jovens escutam os ensinamentos e é ali que 
todas as decisões importantes são tomadas. Na aldeia, a preparação de alimentos e tudo o mais acontece à beira do fogo, por isso muitas vezes eles e suas vestes ficam com o odor característico da fumaça, o que pode fazer com que os colegas não indígenas se afastem. Essa diferença cultural ocorre inclusive com indígenas que ingressam em cursos superiores. Em depoimento ao Jornal da Universidade, um estudante indígena de Direito da Universidade Federal do Rio Grande do Sul (UFRGS) disse que a diferença cultural pode levar estudantes indígenas até mesmo a desistirem de estudar: "A pessoa que não conhece indígena não se sente bem, não sabe como lidar" (CARDOSO, 2015, p. C4).

O idioma também pode ser uma barreira. Nesta Escola Indígena, as crianças convivem desde muito cedo com professores não indígenas e ainda assim chegam ao Ensino Médio com dificuldade de comunicação em português. Quando aqueles dois alunos ingressaram em escolas não indígenas, o idioma foi determinante para que eles, algum tempo depois, desistissem de continuar os estudos naquelas escolas.

Já os outros oito alunos estudaram sempre nesta escola, e para eles é muito natural que o cheiro da fumaça e pessoas falando em Guarani e em português convivam em harmonia. E assim o processo de escolarização vai se dando na escola da aldeia, respeitando o ritmo de cada um e com tranquilidade.

Se a escola foi uma demanda da comunidade e se o Ensino Médio diferenciado partiu da vontade dos indígenas, surge a segunda pergunta: Por que você está fazendo Ensino Médio? O que você pretende fazer quando terminar o Ensino Médio?

As respostas mostraram que os alunos desejam ser aceitos também fora da aldeia e cinco deles manifestaram desejo de ingressar na universidade. Isso já é uma tendência nesta comunidade, na qual é bem difícil viver apenas da agricultura e do artesanato. A esse respeito uma aluna escreve: "Para melhorar de vida e aprender os costumes dos brancos. Se preparar para fazer faculdade. Pretendo trabalhar" [sic]. Esta resposta demonstra a procura desse grupo por melhores condições de vida. Nesse sentido Cardoso (2015), em sua reportagem sobre estudantes indígenas na UFRGS, também detectou o estímulo que jovens indígenas recebem dos pais e das lideranças da tribo para estudar. Um indígena 
estudante de Direito optou pela carreira jurídica para defender os direitos de seu povo: "Sempre ouvia que os direitos indígenas não eram respeitados. Funcionários da Funai [Fundação Nacional do Índio] e do Ministério Público nos diziam que precisávamos de alguém qualificado na área” (p. C4).

Os alunos que não manifestaram desejo de ingressar na universidade responderam que pretendem conseguir um emprego formal fora da aldeia. Percebe-se que houve uma mudança ao longo do tempo, pois se antes da regulamentação da educação indígena o desejo da escolarização era com o intuito de poderem buscar os seus direitos, hoje além disso buscam se inserir na comunidade não indígena e por ela serem aceitos. Constatação semelhante foi feita por Lopes (2015) em uma aldeia indígena da etnia Bakairi, no Mato Grosso, em que observou que "os conteúdos escolares são colocados, sobretudo, em função da relação com os não indígenas" (p. 250), e que "os alunos aspiram, então, a diversas formações profissionais, além das licenciaturas - primeiros cursos de graduação ofertados aos estudantes indígenas” (p. 253) naquele Estado.

Uma vez que, de acordo com o Referencial Curricular Nacional para as Escolas Indígenas, esta escola deve atender aos interesses dos indígenas, lhes foi perguntado: Considera a metodologia, isto é, o jeito dos professores darem aula, adequado?

Todos os alunos disseram ser adequada a metodologia, mas talvez isso possa ser atribuído ao fato de a maioria deles conhecer apenas esta realidade. A esse respeito um aluno escreve: "Os professores ensinam a gente a estudar e a gente está ali pra aprender" [sic] o que reflete muito bem o fato de deixarem a cargo do professor não indígena a tarefa de prepará-los para serem aceitos na sociedade fora da aldeia, achando válidas todas as práticas pedagógicas. Outro aluno se manifesta a esse respeito da seguinte forma: "Sim, por que os professores vêm ensinando para nós enfrentar um mundo diferente do nosso. Então por isso o que eles estão fazendo na escola são adequados" [sic]. Percebe-se nas respostas o respeito e a confiança depositada pelos alunos na escola e em seus professores. 
Outro questionamento apresentado foi: Os ensinamentos Guaranis são passados basicamente de forma oral, e os ensinamentos da escola são passados basicamente de forma escrita. Como você faz para se adaptar a esse modo do "branco" dar aula?

Nas respostas pode-se perceber que todos dão muita importância ao registro escrito de dados, tanto para não esquecer o que foi trabalhado em sala de aula quanto como forma de inserção na sociedade não indígena, mas sem perder a sua identidade. A esse respeito um aluno escreve: 'É bom quando o branco dá aula, mas nossa língua Guarani não pode ser esquecida mesmo que o branco der aula" [sic], o que demonstra uma constante preocupação com as suas origens e a preservação da sua cultura.

Lopes (2015) observou fenômeno semelhante em seu estudo com os índios Bakairi, no Mato Grosso: "A escrita tem lugar no contexto da escola Bakairi como instrumento de captura de recursos de propriedade dos brancos, os 'civilizados'. [...] a escrita escolar também se refere à captura de recursos, então pode ser considerada um instrumento de poder" (p. 251), mas a autora acrescenta:

Para os Bakairi, adotar um comportamento de branco significa que ele estaria assumindo, provisoriamente, conforme necessidade naquele momento, a identidade de branco, mas isso não implicaria no abandono de sua identidade de índio, muito menos na transformação definitiva em branco, ou seja, na perda definitiva de sua identidade bakairi (LOPES, 2015, p. 251).

Em contrapartida o desejo e a necessidade deles se inserirem em outra sociedade, pautada em princípios diferentes dos seus, faz com que aceitem esta metodologia e se adaptem a ela, como escreve um aluno:

Hoje em dia nós precisamos muito aprender a escrita por que sem ter a escrita não podemos competir com a sociedade branca que só vive da escrita. Por isso precisamos nos adaptar a todas as maneiras do branco dar aula [sic].

Isso também pode ser reflexo da intenção de entrar na universidade, por exemplo. 
Uma vez que se sabe que a escola indígena deve ser diferenciada e mantida por sua vontade, atendendo as suas necessidades, respeitando a sua cultura, mas a aula do Ensino Médio não é ministrada por professor Guarani, deve existir uma adaptação mútua que proporcione o aprendizado. Assim sendo, foi perguntado aos alunos: Como você faz para se adaptar à forma de cada professor dar aula? Percebe-se nas respostas que o fato de os alunos entenderem que os conhecimentos da escola devem ser passados de forma escrita, ao contrário dos conhecimentos dos Guaranis, que são passados de forma oral, faz com que para eles a adaptação passe pelo registro escrito. A manifestação "Eu me adapto quando o professor escreve no quadro e explica bem direitinho as matérias pra os alunos" [sic] reforça que a atitude de copiar é parte do desejo de aprender.

Os estudantes têm consciência de que o ambiente escolar em que se encontram é diferenciado com relação ao da Escola do Campo na qual estão formalmente matriculados, assim como também é diferenciado se comparado a outras escolas da rede estadual de ensino. Eles também têm consciência de que quando, ou se, entrarem na universidade, esse olhar diferenciado vai desaparecer, constituindo um motivo de preocupação. Provavelmente por isso uma aluna escreve:

Cada professor dar aula do seu jeito. Tem professor que dar aula difícil, mas mesmo assim é bom, por que se algum dia fazer faculdade a gente já vai saber alguma coisa que aprendeu na escola” [sic].

As turmas multisseriadas são uma determinação da Coordenadoria Regional de Educação quando há poucos alunos matriculados, não levando em conta a especificidade destas turmas. A esse respeito lhes foi feita a pergunta: Como você se sente em turmas multisseriadas, isto é $1^{\circ}, 2^{\circ}$ e $3^{\circ}$ anos juntos? O que tem de bom e o que não é bom?

O grupo de alunos considera essa prática muito acertada, por fortalecer os seus laços de amizade e, segundo eles, favorecer a aprendizagem. Assim, um aluno escreve: "Eu me sinto bom por que quando a gente estuda junto temos mais colegas para nos ajudar quando não sabe a matéria” [sic]. Eles já estiveram em turmas multisseriadas no Ensino Fundamental, assim a presente 
realidade não é novidade, mas não têm consciência das adaptações que precisam ser feitas pelo professor para que isso se viabilize, e nem das perdas que possam estar ocorrendo no seu aprendizado.

A prática de turmas multisseriadas na educação indígena é muito comum e bem aceita, como argumenta Bergamaschi (2007b) a respeito dos anos iniciais da Educação Básica:

As escolas que observei são, no nosso dizer, multisseriadas e, assim como convivem pessoas de diferentes idades, também convivem diferentes níveis de conhecimento: algumas leem com fluência e conhecem as letras para articular a escrita de muitas palavras, enquanto outras estão realizando o primeiro contato com as letras (p. 235).

O mesmo ocorre nesta turma de Ensino Médio, em que alunos das três séries estudam juntos, auxiliando uns aos outros em sua língua materna. A prática na sala de aula mostra que isso nada tem a ver com não querer interagir com o professor não indígena, é apenas o jeito e Guarani aprender, eles aprendem uns com os outros e por isso as turmas multisseriadas estão de acordo com o espírito de coletividade desses alunos.

Sem dúvida a presença da escola dentro da aldeia, no decorrer desta década e meia, de algum modo a impactou. Com o objetivo de saber de que forma, na visão dos estudantes, ocorreu esse impacto, foram feitas duas perguntas. A primeira: $\mathrm{O}$ que a escola trouxe de bom para a aldeia? Todos os alunos concordaram quanto aos benefícios da escola para a aldeia no que diz respeito à inserção dos indígenas na sociedade não indígena. A resposta de um aluno foi: "A escola trouxe aprendizagem para nós. Nos ensinou muita coisa para se adaptar na sociedade do branco que não é do nosso mundo" [sic]. Projetos de saúde e meio ambiente, de nutrição, horta comunitária, prevenção de doenças e destinação de resíduos têm sido trabalhados na escola, juntamente com o posto de saúde, que também fica dentro desta reserva indígena. O presente trabalho tem rendido bons frutos e foi lembrado por uma aluna: "Coisas importantes para adultos e para crianças, para cuidar do ambiente para melhorar a vida, cuidar da aldeia, para as crianças aprender coisas boas" [sic]. 
Já na segunda pergunta: O que a escola trouxe de ruim para a aldeia?, apenas um aluno disse que a escola trouxe algum malefício para a aldeia: " $A$ infiltração em nossa cultura o que mais nos trouxe de ruim é a tecnologia" [sic]. Todos os outros estudantes consideraram benéfica a existência da escola dentro da reserva, uma vez que esta contribui para a inserção do indígena na sociedade não indígena. Tal fato está de acordo com a expectativa que eles depositam na escola com relação ao seu futuro, como manifesta por escrito outro aluno: " $A$ escola não trouxe de ruim para nossa aldeia, trouxe coisas boas, como educação, escrever melhor, aprender a ler" [sic].

\section{As Impressões dos Professores da Escola Indígena}

Nesta aldeia Guarani existem professores não indígenas que trabalham com o Ensino Médio e os professores Guaranis, que não trabalham com Ensino Médio, mas que foram entrevistados com a finalidade de se compreender a visão que eles têm desse nível de ensino. São cinco os professores Guaranis que atuam na escola: um é concursado para o magistério público estadual e os quatro outros são contratados pela CLT, em "contrato emergencial". Quatro deles foram alunos desta mesma escola no Ensino Médio e o outro foi professor de todos eles na fase de alfabetização. Além da diretora, que não é indígena, os professores de origem não indígena de Ensino Médio são sete, entre os quais se inclui a primeira autora do presente texto.

Inicialmente perguntou-se aos professores sobre sua formação. Uma peculiaridade da educação escolar indígena é que não há obrigatoriedade de cursar uma Licenciatura (ou qualquer curso superior) para fazer concurso público e ser nomeado como professor indígena para as séries iniciais. Já para dar aula no Ensino Médio é necessário ter a Licenciatura na área correspondente.

A primeira pergunta feita foi: Professor(a), você teve algum curso de formação para educação indígena que o preparasse para esta realidade em particular? Caso tenha, fale a respeito. As respostas mostraram que apenas dois professores indígenas tinham realizado o curso para capacitação em magistério indígena Guarani “Киаa Mbo'e = conhecer-ensinar”. Segundo depoimento de 
um desses professores, "Esse curso era dado por professores indígenas e "juruá', se falava muito de nossa tradição e de nossas lendas, mas não ensinava a dar aulas. Depois esse curso terminou e ninguém mais fez" [sic]. Como desde 2003 esse curso não foi mais oferecido, os outros professores de origem Guarani entrevistados não realizaram esse tipo de capacitação e responderam estar aprendendo na prática, ao acompanharem os professores "juruá".

Os professores não indígenas não participaram de qualquer tipo de curso de formação para trabalhar com esta realidade. Alguns participaram de oficinas, ou encontros de formação, sempre após já estarem trabalhando nesta escola e com enfoque em séries iniciais e Ensino Fundamental. Uma professora comenta:

Nunca participei de nenhum curso preparatório para trabalhar com educação indígena. Muitos "encontros de formação" foram proporcionados, dos quais participei. Serviram de reflexões sobre a cultura Guarani, bem como sobre a pedagogia e metodologia utilizada [sic].

De acordo com o Referencial Curricular Nacional para as Escolas Indígenas (RCNEI), esta escola deve ser: “... pensada a partir das concepções dos indígenas e das suas formas de organização social, política, cultural, econômica e religiosa" (BRASIL, 1998a, p. 20). Assim, uma pergunta para os professores foi: Na sua opinião, esta escola em que você trabalha está pensada a partir desta concepção? Por quê?

Os professores indígenas afirmaram que a escola no início não foi pensada como uma escola diferenciada e sim uma escola com o único objetivo de inserir o indígena no mercado de trabalho fora da reserva, como meio de buscar o sustento, e para tanto o domínio da língua portuguesa e de alguns costumes não indígenas seriam fundamentais. Hoje consideram que a escola é importante para "[... ] registrarmos a nossa cultura além de buscarmos outros meios de sustentar as nossas famílias" [sic]. Assim, a concepção dos indígenas em relação à escola mudou com o passar do tempo e a escola deixou de ser importante para garantir o sustento e passou a ser vista como um meio para mudar a sua própria vida. Esse fato nem sempre é bem-visto, principalmente pelos mais velhos, que temem que os jovens venham a perder o seu "Nhande Reko". 
$\mathrm{Na}$ opinião dos professores entrevistados, a escola está de acordo com os preceitos do RCNEI, atendendo às suas necessidades. Um deles afirma que o ensino da religião dos Guaranis não cabe à escola, pois

tem coisas que se ensinam na beira do fogo ou na casa de rezas, são coisas que só "Kunhã Kara1"” tem como ensinar e aconselhar, isso não é da escola, mas aqui a gente ensina os valores da cultura, como se comportar quando sai da aldeia que é para representar bem o nosso povo lá fora [sic].

O que já foi mencionado por Martins (2013, p.279) quando se refere à “...importância de se reconhecer os diversos espaços que o aluno transita” e quando diz que “... a educação tradicional sai de dentro da casa (“Opy”), por isso tem que ser preservada, não ficar mostrando".

Isso, contudo, só ocorre para turmas do Ensino Fundamental. Como o Ensino Médio não pertence à Escola Indígena, esse olhar diferenciado das concepções ocorre de acordo com o entendimento de cada professor e orientação da direção da escola, uma vez que não faz parte do regimento da Escola do Campo à qual pertencem essas turmas.

As perguntas a seguir foram feitas com a intenção de se verificar o quanto a escola está adaptada ao que está disposto no RCNEI. De acordo com esse Referencial, a escola deve apresentar certas características, que foram analisadas pelos professores.

a) Comunitária: "Porque conduzida pela comunidade indígena, de acordo com seus projetos, suas concepções e seus princípios. Isso se refere tanto ao currículo quanto aos modos de administrá-la. Inclui liberdade de decisão quanto ao calendário escolar, à pedagogia, aos objetivos, aos conteúdos, aos espaços e momentos utilizados para a educação escolarizada" (BRASIL, 1998a, p. 22). Na sua opinião, esta escola atende aos quesitos para ser considerada comunitária?

${ }^{8}$ Kunhã Karaí: Chefe espiritual mulher, responsável pelo cuidado na aldeia Guarani. 
Nesse item as críticas dos professores indígenas foram muitas. Um problema identificado foi a merenda escolar, pois o cardápio é feito por uma nutricionista que não é especialista em alimentação indígena e muitos itens da cultura Guarani não são contemplados no dia a dia, embora a escola tente adaptar o cardápio, quando possível.

Quanto ao calendário escolar foi dito por um dos professores indígenas:

[...] para nós o fim de ano tem que ser em junho, julho. E as férias em julho, agosto e setembro, que é a época de prepararmos a terra para nossas plantações. Lá no Referencial diz que temos que ser ouvidos no calendário, mas qual é o professor "juruá" que vai querer trabalhar no verão e ficar de férias no inverno? Nem a coordenadoria aceita, então isso está no referencial mas não pode ser feito [sic].

O calendário escolar revela-se, assim, um ponto de tensão. E não é só uma questão de férias, mas também de feriados. Assim como ocorre na maior parte das escolas da rede estadual, é pouco comum se ter um professor que trabalhe exclusivamente nesta escola. Por isso é muito difícil conciliar as datas comemorativas e feriados dos indígenas com os não indígenas, tendo-se contado com o bom senso de ambas as partes para negociar e chegar a um acordo no âmbito desta escola.

Se por um lado os conteúdos devem respeitar as concepções indígenas, não existe material didático produzido de acordo. Assim sendo, os livros do Programa Nacional do Livro Didático (PNLD) enviados pelo Ministério da Educação para esta escola são os mesmos enviados a todas as outras. A respeito disso um professor indígena comenta:

[...] o descobrimento das Américas eles dão de acordo com a visão do europeu, mas o índio já estava aqui. Ou no corpo humano só se fala sobre os órgãos sexuais a partir dos 14 anos, os pais falam com os meninos e as mães falam com as meninas, e mesmo assim tem coisas que só se falam depois do casamento e na escola a professora sai falando sem respeitar a nossa cultura [sic]. 
No trabalho de Lopes (2015) também foi apontada, por um indígena Bakairi do Mato Grosso a falta de material didático específico para esta modalidade de ensino:

Se tiver no livro, é cultura de outra [...]. Agora daqui estuda também. Por isso, estuda os dois, a que vem de lá de fora e daqui da cultura, a história, a pesca, essas coisas [...] (ex-aluno da EJA).

Uma ação do Ministério da Educação (MEC) (BRASIL, 2007) fomentou a produção de materiais didáticos bilíngues ou multilíngues para uso em comunidades indígenas. No Rio Grande do Sul a ação "Saberes indígenas na escola" integra o programa de formação continuada do MEC destinado a professores que atuam nos anos iniciais da Educação Básica, em colaboração com docentes da UFRGS (SILVEIRA, 2016). Nesta ação foi elaborado, pela totalidade (59) de professores Guarani do Estado, um material didático, lançado em 2016, que oficializa o alfabeto Guarani, que até então gerava controvérsia quanto à grafia, e cujos textos e ilustrações são de autoria exclusiva dos indígenas. O material aborda aspectos como o plantio de sementes tradicionais e o calendário Guarani dividido em duas estações, o período de plantações e colheitas e o inverno. Observa-se, entretanto, que a lacuna de material didático voltado à educação escolar indígena no Ensino Médio persiste.

Outra característica da escola, de acordo com o RCNEI, deveria ser:

b) Intercultural: "Porque deve reconhecer e manter a diversidade cultural e linguística; promover uma situação de comunicação entre experiências socioculturais, linguísticas e históricas diferentes, não considerando uma cultura superior à outra; estimular o entendimento e o respeito entre seres humanos de identidades étnicas diferentes, ainda que se reconheça que tais relações vêm ocorrendo historicamente em contextos de desigualdade social e política." $\mathrm{Na}$ sua opinião, esta escola atende aos quesitos para ser considerada intercultural? (BRASIL, 1998a, p. 22).

Foi possível perceber que, sob a ótica dos professores entrevistados, de fato esta escola é intercultural, uma vez que respeita a língua e a cultura Guaranis. Embora, como abordado anteriormente, determinados conteúdos não 
estejam de acordo com a cultura Guarani, os indígenas consideram que esses assuntos são "da escola" e não "da comunidade". Como muitos dos membros da aldeia não entendem que a escola é "da comunidade", eles não se apropriam dela. Alguns pensam que os ensinamentos da escola são só da escola e por isso não questionam quando os conhecimentos abordados se chocam com a cultura indígena. Bergamaschi (2007a) comenta, a esse respeito, que a escola situada na aldeia é constituída a partir de uma concepção de mundo diferente da do povo Guarani. Mesmo assim, os indígenas da aldeia sentem-se respeitados e valorizados, uma vez que muitas coisas nesta escola são decididas e organizadas junto com a comunidade.

A diversidade linguística na sala de aula é bem pronunciada, porque o professor dá a sua aula em português e depois as dúvidas dos alunos são resolvidas diretamente com o professor, em português, ou entre os alunos, em Guarani, coexistindo pacificamente os dois idiomas. O próprio Plano Político-Pedagógico (PPP)9 da escola expressa:

\begin{abstract}
É importantíssimo se embasar nos valores culturais de cada comunidade em diferentes costumes [...], pois sabemos que alguns valores deixaram de ser praticados. Que o currículo privilegie e leve em consideração as situações que possibilitem a prática na comunidade de cada ritual [...]. Que valorize o uso das ervas medicinais, das frutas e dos alimentos naturais, a retomada de valores culturais (histórias e mitos), a preservação do meio ambiente, a terra. Daí vem a importância de uma proposta de ensino que reforce esse tipo de resgate nas comunidades.
\end{abstract}

A única ressalva é de que esse PPP é da Escola Indígena, de Ensino Fundamental, uma vez que, no PPP da Escola do Campo que se responsabiliza pela turma de Ensino Médio não existe qualquer consideração especial para esta turma. Se a educação indígena fosse incluída no PPP desta Escola do Campo, poderia garantir a estes alunos algumas peculiaridades na sua educação escolar, que hoje eles não têm asseguradas.

${ }_{9}$ O PPP não está publicado, encontra-se disponível para consulta na Direção da Escola. 
Mesmo assim um professor não indígena declara: "Existe um grande respeito com relação à cultura Guarani, desta forma, a escola procura fazer um resgate cultural do índio e da sua vivência". O que de fato se pretende é trabalhar as duas culturas e fortalecer a cultura Guarani. Já uma professora indígena disse: "[...] o branco respeita a cultura do Guarani ensinando de acordo com algumas coisas que a comunidade propõe para a escola".

Esse grupo de Guaranis, alunos e professores, dá importância à escola, na tentativa de se inserir numa sociedade externa à sua, e procura fazê-lo por meio do estudo. Um dos professores indígenas afirma:

Promove sim. Pois trabalha o conhecimento dos indígenas pelos indígenas e as questões culturais dos "juruá" pelos "juruá". Mas uma cultura sempre se sobrepõe à outra, a do "juruá" se sobrepõe. E isso não é ruim por que se a gente quer entrar na universidade precisa desse conhecimento que está se sobrepondo, não tem como ficar só estudando em Guarani e tudo de acordo com a nossa cultura e depois querer entrar na faculdade, não vai conseguir. Só se tivesse universidades indígenas [no Rio Grande do Sul] como na Bolívia e no Paraguai, mas aqui não tem, então não dá mesmo para fazer tudo o que o RCNEI diz, dá prafazer só em partes. Mas o governo deveria dar um jeito de criar essas universidades para que daí se pudesse fazer bem como diz no RCNEI [sic].

Nota-se que o "Nhande Reko" é muito forte, em nenhum momento se cogita a possibilidade de perda de identidade e sim de trocas culturais com as quais todos saem ganhando, alunos, professores indígenas e não indígenas. Então, quando o professor observa que a cultura do branco se sobrepõe à cultura Guarani, ele está se referindo ao fato de se apropriarem de uma cultura que não é a deles para benefício próprio. Assim sendo, não se trata de que a escola não esteja promovendo a interculturalização e sim de que cada professor branco, juntamente com a direção da escola, está lhes fornecendo ferramentas para que cada um possa seguir o seu caminho após a conclusão do Ensino Médio.

Nesse aspecto, essa escola parece ser um pouco diferenciada do que ocorre em geral nas escolas situadas em aldeias indígenas. Silveira (2016), em sua já mencionada reportagem, entrevistou um orientador de estudos de um grupo de participantes Guaranis do curso de formação anteriormente referido. 
Este líder observa que há dificuldade da própria escola em respeitar a tradição e a cultura Guaranis. As adaptações deveriam ocorrer tanto em conteúdos quanto em aspectos administrativos. O educador exemplifica com a situação que ocorre quando uma menina Guarani "fica mocinha". Ela deve se resguardar por duas semanas dentro de casa. Ao visitar as escolas, o educador observou que os professores Guaranis não davam faltas para as alunas, enquanto que os professores não indígenas registravam as faltas (SILVEIRA, 2016). Talvez a diferença da escola aqui investigada venha do diálogo que se estabelece, pois o cacique da aldeia é professor da escola e a direção é bastante sensível às demandas da comunidade.

c) Bilíngue: “... as tradições culturais, os conhecimentos acumulados, a educação das gerações mais novas, as crenças, o pensamento e a prática religiosos, as representações simbólicas, a organização política, os projetos de futuro, enfim, as reproduções socioculturais das sociedades indígenas são, na maioria dos casos, manifestadas através do uso de mais de uma língua" (BRASIL, 1998a, p. 23). Na sua opinião, esta escola atende aos quesitos para ser considerada bilíngue?

O grupo de professores entende que de fato a escola é bilíngue, uma vez que os dois idiomas não são conflitantes e sim complementares. Uma professora Guarani diz: "no ensino fundamental tem aula de Guarani e no médio [...] os alunos falam em Guarani e os professores não se importam”. A língua materna é o modo de comunicação entre os alunos, mesmo dentro da escola. O português, embora fluente, é a segunda língua e é utilizada apenas no âmbito escolar.

Do mesmo modo, as crenças e tradições também encontram abrigo na escola. Para as turmas de Ensino Fundamental, isso ocorre na sala de aula. Para as turmas de Ensino Médio são acolhidas no dia a dia e em datas comemorativas. Se constasse do PPP da Escola do Campo, a língua Guarani, a sua literatura e os seus valores poderiam ser trabalhados com as turmas de Ensino Médio. O oferecimento de turma específica de educação indígena no Ensino Médio deveria ser incluído no PPP da Escola do Campo, para viabilizar essas práticas.

d) Específica e diferenciada: “... concebida e planejada como reflexo das aspirações particulares do povo indígena e com autonomia em relação a determinados aspectos que regem o funcionamento e orientação da escola não indígena. Todo 
projeto escolar só será escola indígena se for pensado, planejado, construído e mantido pela vontade livre e consciente da comunidade" (BRASIL, 1998a, p. 23). Na sua opinião, esta escola atende aos quesitos para ser considerada específica e diferenciada?

Em nenhum momento se pretende fazer uma escola tão específica e diferenciada que não permita ao indígena a inserção em uma sociedade não indígena, até por que esta reserva encontra-se na Região Metropolitana de Porto Alegre. São aproximadamente 120 habitantes vivendo em sete hectares, às margens de uma rodovia estadual, mostrando-se inevitável a troca de experiências. Por esse motivo um professor indígena reflete:

a escola tem coisas que tem que ser igual a escola do "juruá" para que a gente possa aprender a lidar com vocês e a gente poder aprender a lutar por nossos direitos, se não fica fácil o "juruá" nos dominar e não respeitar nossos direitos [sic].

Se por um lado os RCNEI pregam uma escola diferenciada, por outro a amarram à burocracia, não lhe dando autonomia financeira, por não reconhecer que as demandas da escola indígena são diferentes das demandas das outras escolas, não indígenas. Aqui identificam-se conflitos. Assim explica um professor indígena da escola:

Eu sou professor mas também sou cacique e se eu tenho que viajar para atender os interesses da minha aldeia eu tenho que pedir autorização para a CRE e se eu não venho trabalhar eu preciso de atestado. Então a escola funciona como o Estado quer, no papel tem que ser diferenciado, mas na prática ela não é por que eles mesmos não deixam [sic].

Para viabilizar a diferenciação da escola é necessário adaptar currículo e prática pedagógica. Para os povos indígenas a transmissão do conhecimento se dá de forma oral. É necessário que o professor entenda essa peculiaridade e saiba se adaptar, embora os alunos no Ensino Médio já tenham compreendido que a quantidade de conhecimentos não é possível de ser assimilada verbal- 
mente, preferindo a escrita para as práticas escolares. Também os professores indígenas já aderiram a esta prática, com a escrita constituindo mais uma forma de inserção, como expressou um professor indígena:

A escrita não tira nada da cultura Guarani, só acrescenta. Pra nós é muito bom, é uma ferramenta a mais para passar o conhecimento e a nossa cultura para o nosso povo. Mesmo assim a gente não vai perdendo. As coisas do nosso povo a gente aprende com os parentes e na "Opy", mas é importante o registro escrito para sempre ir passando. [sic].

Assim, quando um adolescente sai da escola indígena para a universidade ou para buscar outro modo de sustento, o seu "Nhande Reko" já está arraigado e com menos chances de ser perdido. Como diz o cacique desta aldeia: "A gente tem que pegar o conhecimento do branco que nos interessa sem perder a cultura Guarani” [sic]. Outro professor indígena se expressa assim:

As questões de diálogo entre a sociedade indígena e não indígena também é bom. E o registro do conhecimento do indígena pelo indígena, agora a gente tem condições de dizer o que a gente pensa então precisa do "juruá" pra falar e escrever por nós [sic].

Outros professores consideram que as relações interpessoais foram afetadas, conforme argumenta um professor Guarani: “mudou o 'Nhande Reko' principalmente por que antes se pensava muito na coletividade e hoje é muito individual, hoje são mais individualistas e capitalistas" [sic]. E quando questionado se isso foi ocasionado pela escola, ele responde: "A escola veio com o 'juruá' e foi isso que contaminou, hoje não é mais que nem antigamente, agora o índio está pensando que nem o 'juruá'” [ [sic]. Esta visão é compartilhada pelos professores não indígenas, que concordam que o tempo do branco é diferente do tempo dos indígenas, que eles precisam refletir profundamente antes de tomar decisões, mas mesmo assim, tanto os professores indígenas quanto os não indígenas fazem uma avaliação positiva da escola dentro da reserva. 


\section{O Desafio de Trabalhar em uma Turma Multisseriada}

No caso desta escola as turmas de Ensino Médio indígena são multisseriadas. A escolarização em turmas multisseriadas é um desafio que os Guaranis vêm enfrentando para assegurar o seu direito a estudar na pequena comunidade onde vivem, trabalham e produzem a sua subsistência. No levantamento bibliográfico feito para o presente trabalho, não foram encontradas referências que tratassem especificamente de classes multisseriadas na educação indígena. Por isso, escolheu-se apresentar algumas ideias sobre classes multisseriadas na educação do campo, que foram consideradas relevantes para a realidade desta escola indígena.

Segundo Hage (2011), as Escolas do Campo localizam-se em pequenas comunidades, em que a população a ser atendida não atinge o contingente definido pelas Secretarias de Educação para formar uma turma por série. É exatamente o que acontece nesta aldeia, com a particularidade de todos os jovens da aldeia, em condições de se matricularem no Ensino Médio, estão efetivamente matriculados. Percebe-se uma ambiguidade na dinâmica de trabalho nas turmas multisseriadas, reflexo do descaso com que é tratada a educação quando o número de alunos é reduzido. São impedidos de estudar em turmas separadas, embora tenham assegurado por lei o mesmo direito à escolarização básica que qualquer outro estudante. Ao mesmo tempo, as possibilidades construídas pelos educadores, gestores e membros da comunidade escolar evidenciam situações criativas, que desafiam as condições adversas da realidade dessa turma.

Nesta modalidade de trabalho ocorre a sobrecarga dos professores, uma vez que é necessário manter um rigoroso registro, através dos anos, de quais conteúdos cada aluno já viu e de que forma foram abordados na ocasião, com o objetivo de não cair em repetições. Não que elas não possam ocorrer, mas quando for necessário, que os alunos tenham outra abordagem, com o objetivo de mostrar outros aspectos ainda não trabalhados e de desafiá-los para novas formas de pensar e descobrir. Por isso, as turmas multisseriadas geram angústia para o professor, que não foi preparado para esta realidade. O professor tem duas opções, ou trabalha com currículo único com todos os alunos, ou atende a sala em grupos diferentes de maneira simultânea. De acordo com Hage (2011), 
sem uma compreensão mais abrangente desse processo, muitos professores organizam o seu trabalho pedagógico sob a lógica da seriação, desenvolvendo suas atividades educativas referenciados por uma visão de "ajuntamento" de várias séries ao mesmo tempo, elaborando planos de ensino e estratégias de avaliação da aprendizagem diferenciadas para cada série. Como resultado, os professores sentem-se angustiados e insatisfeitos por pretenderem realizar o trabalho da melhor forma possível e se considerarem perdidos e impotentes diante da situação.

A esse respeito a diretora da escola diz: "As turmas multisseriadas é um critério adotado pelo número de alunos e não pela especificidade da cultura" [sic]. Se para a Coordenadoria Regional de Educação (CRE) é apenas uma questão de número de alunos e professores, para os Guaranis o fato é muito mais sério, pois para eles isso pode ferir a sua cultura, como expressa um professor indígena:

assim não respeita as idades, está tudo junto e não é tudo que todos podem escutar. Isso não respeita a nossa cultura. [...] o governo acha que são poucos alunos e isso não tem nada a ver, porque são todos os que temos, eles deveriam respeitar isso.

Uma estratégia que poderia ser utilizada para driblar esta situação seria o livro didático, mas, como já foi discutido, não existe livro didático de Ensino Médio específico para educação indígena. E mesmo que existisse, a turma aqui investigada não pertence oficialmente a uma escola indígena, assim sendo, talvez nem os recebessem. Uma pequena contribuição para amenizar esse problema foi relatada por Silveira (2016) em sua reportagem sobre a elaboração de material didático específico para a educação indígena, mas apenas para o Ensino Fundamental, não para o Ensino Médio.

Embora os professores indígenas e não indígenas tenham se manifestado contra as turmas multisseriadas, por entender que ocorrem perdas no aprendizado, os alunos, como já foi visto, não compartilham desse entendimento. Para eles 
o senso de coletividade e de ajuda mútua na língua materna é tão forte que de fato eles entendem que as turmas multisseriadas são o melhor caminho para garantir a sua escolarização.

\section{Sobre a Prática Pedagógica Nesta Aldeia Guarani}

A seguir apresenta-se o depoimento pessoal da primeira autora do presente trabalho a respeito de sua própria experiência docente na escola indígena aqui estudada.

"Como já foi mencionado, trabalhar com turmas multisseriadas no Ensino Médio implica muita dedicação, é um desafio diário. Quando comecei a trabalhar na escola indígena, em março de 2007, deparei-me com esta realidade duplamente desafiadora. Tentei, seguindo o exemplo de outros professores que já trabalhavam nesta escola, dividir os alunos por série e trabalhar separadamente, dentro da mesma sala. Esta divisão se mostrou frustrante e pouco produtiva, tanto para mim como para os alunos. A aula não fluía e não havia espaço para discussões, uma vez que era impossível manter um assunto diferente para cada série, simultaneamente. Igualmente difícil era manter um grupo discutindo algum assunto e pretender que os outros fizessem alguma tarefa e não participassem da discussão. Aliás, se não participassem da discussão seria porque aquilo realmente não era interessante, assim era de se avaliar a importância de abordar tal temática. Passei o ano todo neste impasse agonizante, ao qual tanto eu como os outros professores estávamos submetidos.

Hoje entendo que o educando tem um período de três anos para se apropriar de conceitos e processos tecnológicos. Estes podem ser desenvolvidos em vários momentos diferentes, sendo sempre retomados, tanto para não caírem no esquecimento - o que é muito normal de ocorrer, inclusive nas turmas seriadas - como para ressignificar estes tópicos e relacioná-los a outros assuntos. Além do mais, não necessariamente o que é relevante no "mundo do branco" é relevante no mundo do indígena. É nesse momento que temos de lembrar que a 
escola é diferenciada, assim sendo, não só o assunto deve estar conectado com a realidade do estudante, como também deve ser relevante para que ele possa enfrentar o "mundo dos brancos".

Na comunidade indígena a escola não é a única responsável pela educação. Para os Guaranis, a educação não se separa das demais práticas sociais e não fica restrita à casa onde moram, à casa de rezas e tampouco aos conhecimentos construídos nos bancos escolares. Para o povo Guarani, os velhos são como as bibliotecas: sábios que levam consigo a missão de passar os seus ensinamentos aos mais jovens e por isso são profundamente respeitados. Aliás, o respeito é a atitude mais praticada por este povo.

Para aprender, a curiosidade é fundamental, assim como a observação. A oralidade também é muito importante, e neste caso refiro-me a uma oralidade que não se restringe à fala, mas, sim, a uma escuta respeitosa e atenta. Então, seguir a curiosidade natural do povo Guarani e, por meio dela, tecer os conhecimentos escolares, mostrou-se uma técnica de abordagem bem produtiva.

Assim sendo, passei a organizar as minhas aulas na forma de unidades, quando para desenvolver cada uma deveria pensar em quais são os pré-requisitos desta, se já foram trabalhados com alguns dos alunos e de que forma. Assim é possível dar uma nova roupagem e mostrar uma outra faceta do mesmo tema, para dar início à unidade. Dessa forma, os temas podem ser explorados sem vínculo formal com as séries, viabilizando o trabalho em classes multisseriadas".

\section{Conclusões}

A análise da legislação mostrou que a educação indígena deve ser diferenciada e deve atender às necessidades específicas de cada povo. Na escola estudada no presente trabalho, nem todas as questões culturais são atendidas, pois alguns temas são abordados de uma forma não condizente com a tradição do povo Guarani. Verificou-se, ainda, na legislação, que não há diretrizes específicas para ensino de Ciências da Natureza para o Ensino Médio indígena. As regulamentações existentes são apenas para o Ensino Fundamental. 
Nem sempre os pressupostos gerais da legislação para a educação indígena conseguem ser adequadamente aplicados na realidade desta escola, especialmente no Ensino Médio. Isso porque não existe material didático específico e também pela inexistência, atualmente, de cursos de formação continuada para professores de origem não indígena que atuam nesta modalidade educacional. Uma das principais dificuldades apontadas pelos professores de Ensino Médio que atuam nesta escola é a imposição de trabalhar em classes multisseriadas. Por outro lado, para os próprios estudantes indígenas isso não parece ser um problema. Eles apontam a troca de ideias e o auxílio dos colegas, prestado em Guarani, como aspectos fortemente positivos para a aprendizagem.

Espera-se que o presente trabalho possa contribuir para que outros professores que atuam nesta comunidade, bem como outros pesquisadores que venham a desenvolver trabalhos junto a esta aldeia, tenham uma melhor compreensão das aspirações dessa comunidade em relação à educação escolar.

\section{Referências}

ANGROSINO, M. Etnografia e observação participante. Porto Alegre: Artmed, 2009. $138 \mathrm{p}$.

BERGAMASCHI, M.A. Educação escolar indígena: Um modo próprio de recriar a escola nas aldeias Guarani. Cadernos Cedes, Campinas, v. 27, n. 72, p. 197-213, maio/ ago. 2007a. Disponível em: <http://www.scielo.br/pdf/ccedes/v27n72/a06v2772.pdf>. Acesso em: 10 fev. 2017.

. Nhembo'e - Educação escolar nas aldeias Guarani. Educação, Porto Alegre, RS, v. 30, n. 1 (61), p. 109-132, jan./abr. 2007b. Disponível em: <http://revistaseletronicas.pucrs.br/ojs/index.php/faced/article/viewFile/542/378>. Acesso em: 10 fev. 2017.

A temática indígena na escola: ensaios de educação intercultural. Currículo sem Fronteiras, v. 12, n. 1, p. 53-69, jan./abr. 2012. Disponível em: <http://www.curriculosemfronteiras.org/vol12iss1articles/bergamaschi-gomes.pdf>. Acesso em: 10 fev. 2017.

BERGAMASCHI, M. A.; SILVA, R. H. D. Educação escolar indígena no Brasil: das escolas para os índios às escolas indígenas. Ágora, Santa Cruz do Sul, v. 13, n. 1, p. 124-150, 2008. Disponível em: <https://online.unisc.br/seer/index.php/agora/article/ view/113>. Acesso em: 10 fev. 2017. 
BRASIL. Lei n 9.394, de 20 de dezembro de 1996. LDB - Lei de Diretrizes e Bases da Educação Nacional. Disponível em: <http://www.planalto.gov.br/ccivil_03/leis/L9394. htm>. Acesso em: 10 fev. 2017.

. Ministério da Educação e do Desporto. Secretaria de Educação Fundamental. Referencial curricular nacional para as escolas indígenas. Brasília: MEC; SEF, 1998a. Disponível em: <http://dominiopublico.gov.br/download/texto/me002078.pdf>. Acesso em: 10 fev. 2017.

. Ministério da Educação e do Desporto, Secretaria de Educação Fundamental, Departamento de Política da Educação Fundamental, Coordenação Geral de Apoio às Escolas Indígenas. O governo brasileiro e a educação escolar indígena. Brasília: MEC; SEF; DPEF; CGAEI, 1998b. Disponível em: <http://dominiopublico.gov.br/download/ texto/me001784.pdf>. Acesso em: 10 fev. 2017.

. Conselho Nacional de Educação. Resolução CNE/CEB n ${ }^{\circ}$, de 10 de novembro de 1999. Diretrizes Nacionais para o funcionamento das escolas indígenas. Disponível em: <http://portal.mec.gov.br/cne/arquivos/pdf/CEB0399.pdf>. Acesso em: 10 fev. 2017.

. Ministério da Educação. Secretaria de Educação Continuada, Alfabetização e Diversidade. Educação escolar indígena: diversidade sociocultural indígena ressignificando a escola. Cadernos Secad, 3. Brasília: Secad; MEC, 2007.

CARDOSO, E. Indígena conta a experiência de deixar a reserva em que vivia para morar na CEU. Jornal da Universidade, Caderno JU, Porto Alegre: UFRGS, ano 18, abr. 2015, p. C4.

HAGE, S. M. Por uma educação do campo de qualidade social: transgredindo o paradigma (multi)seriado de ensino. Em Aberto, Brasília, v. 24, n. 85, p. 97-113, abr. 2011. Disponível em: <http://emaberto.inep.gov.br/index.php/emaberto/article/download/2488/2445>. Acesso em: 10 fev. 2017.

HOFMANN, A. A. Karai Nhe'e Katu: "aquele que fala sábias palavras" - um campo de discussão da escola indígena entre os Guaranis. In: ANPED SUL - SEMINÁRIO DE PESQUISA EM EDUCAÇÃO DA REGIÃO SUL, 5., 2004, Curitiba. Anais... Curitiba: PUC-PR, 2004. p. 1-14. Disponível em: <http://www.portalanpedsul.com.br/admin/ uploads/2004/Mesa_Redonda/Mesa_Redonda/12_18_22_KARAI_NHE_KATU.pdf>. Acesso em: 10 fev. 2017.

INSTITUTO BRASILEIRO DE GEOGRAFIA E ESTATÍSTICA (IBGE). Censo demográfico 2010. Características da população e dos domicílios: resultados do universo. Rio de Janeiro: IBGE, 2011. Disponível em: <http://biblioteca.ibge.gov.br/visualizacao/periodicos/93/cd_2010_caracteristicas_populacao_domicilios.pdf>. Acesso em: 10 fev. 2017. 
LOPES, E. T. Ensino-aprendizagem de química na educação escolar indígena: o uso do livro didático de Química em um contexto Bakairi. Química Nova na Escola, São Paulo, SP, v. 37 , n. 4, p. 249-256, nov. 2015.

LÜDKE, M.; ANDRÉ, M. E. D. A. Pesquisa em educação: abordagens qualitativas. 9. reimpressão. São Paulo: EPU, 2005. 99 p.

MARTINS, A. M. D. Narrativas: uma inspiração metodológica para as escolas Guarani. In: BENVENUTI, J.; BERGAMASCHI, M. A.; MARQUES, T. B. I. (Org.). A educação indígena sob o ponto de vista de seus protagonistas. Porto Alegre: Evangraf, 2013. P. 277-290.

MORTIMER, E. F. Linguagem e formação de conceitos no ensino de ciências. Belo Horizonte: Ed. UFMG, 2000.

RIO GRANDE DO SUL. Conselho Estadual de Educação. Comissão Especial de Educação Indígena. Parecer $n^{\circ} 383 / 2002$. Estabelece normas para o funcionamento de escolas indígenas no Sistema Estadual de Ensino do Rio Grande do Sul. Disponível em: <http://www.ceed.rs.gov.br/download/20150810113526pare_0383.pdf>. Acesso em: 10 fev. 2017.

SILVEIRA, J.C. Cultura indígena impressa. Jornal da Universidade, Porto Alegre: UFRGS, ano 19, maio 2016, p. 8.

TASSINARI, A. M. I. Escola Indígena: novos horizontes teóricos, novas fronteiras de educação. In: SILVA, A. L.; FERREIRA, M. K. L. (Org.). Antropologia, História e Educação. A questão indígena na Escola. São Paulo: Global, 2001. p. 45-70. 